\title{
El prestigio de Francia en la vida artística y social de Santa Cruz de Tenerife (1850-1900)
}

\section{Carlos Javier Castro Brunetto}

\section{(2) OpenEdition \\ 1 Journals}

Edición electrónica

URL: https://journals.openedition.org/cher/434

DOI: $10.4000 /$ cher.434

ISSN: 2803-5992

Editor

Presses universitaires de Strasbourg

\section{Edición impresa}

Fecha de publicación: 10 junio 2021

Paginación: 21-47

ISBN: 9791034400928

ISSN: 1968-035X

Referencia electrónica

Carlos Javier Castro Brunetto, «El prestigio de Francia en la vida artística y social de Santa Cruz de Tenerife (1850-1900)», reCHERches [En línea], 26 | 2021, Publicado el 15 septiembre 2021, consultado el 17 noviembre 2021. URL: http://journals.openedition.org/cher/434 ; DOI: https://doi.org/10.4000/ cher.434 


\title{
El prestigio de Francia en la vida artística y social de Santa Cruz de Tenerife (1850-1900)
}

\author{
Carlos Javier Castro Brunetto*
}

$\mathrm{E}^{1}$ estudio del arte en Tenerife durante la segunda mitad del siglo xIx pasa obligatoriamente por una mención extensa a Francia y su influencia en las Islas ${ }^{1}$. A pesar de la guerra de Independencia y de la derrota napoleónica, de todos es conocido que el gran legado del Siglo de las Luces y de la capacidad militar, cultural y legislativa impuesta por Bonaparte en Europa tuvo consecuencias directas e indirectas sobre la sociedad, la cultura y todas las manifestaciones artísticas después del Congreso de Viena. El Romanticismo literario y artístico convirtió a París en la ciudad de referencia internacional, desbancando cualquier hipótesis de erguir un podio preponderante para Londres o Berlín. La Revolución burguesa de 1830, que aupó a Luis Felipe de Orleans, significó un cambio de paradigma no solo para Francia, sino para la historia de la humanidad. El combate entre la burguesía comercial y la aristocracia terrateniente se saldó con la victoria del Tercer Estado y, en realidad, la proclamación de la breve II República Francesa (1848-1851) y la aclamación de Napoleón III (emperador entre 1851-1870) anunciaron un nuevo credo: el Estado debe buscar un férreo sistema liberal bañado de ciertas dosis de socialismo utópico y cubierto por la fina seda que proporcionaba el romanticismo exaltado.

El embrujo de París deslumbraba en los años centrales del siglo a todos los rincones de Europa que vivían del comercio, pero no alii donde predominaba la explotación de los latifundios, aristocracia terrateniente odiaba al actual París y soñaba con el viejo sistema que representaba Versalles. Obviamente, no era el caso de Canarias, unas islas que, si debían algo al universo, era su privilegiada posición estratégica entre Europa y América, con una tímida mirada hacia

* Carlos Javier Castro Brunetto, Universidad de La Laguna, Grupo de Investigación Arte, Moda e Identidad, ORCID: 0000-0002-1007-8309, <cbrunett@ull.edu.es>.

1 Dedico este trabajo a Carmen Fraga González, catedrática de Historia del Arte de la Universidad de La Laguna, excepcional persona, investigadora, profesora y maestra en los estudios artísticos del siglo xix en Canarias. 
Marruecos y el puerto de Mogador (actual Esauira), donde podían prosperar los comerciantes más avispados; en realidad, Canarias personificaba un precedente algo lejano del sueño americano. El letargo absolutista que encarnaba la ciudad de La Laguna, el decadente comercio del vino que se activaba desde el valle de La Orotava y el ocaso del poder catedralicio de Las Palmas se vio superado en los años centrales del Ochocientos por el dinamismo burgués de Santa Cruz de Tenerife y Las Palmas. En ello colaboró el desarrollo del comercio de la cochinilla como producto de exportación desde ambos puertos, sobre todo desde el tinerfeño. La cochinilla llegó a Canarias en 1825 por Quintero Estévez, aunque su cultivo y producción a gran escala solo puede considerarse en 1846 (Borges et al., 2011: 259-261). La salida de este producto, un parásito de la tunera de excelente cualidad tintórea, alcanzó su cenit entre 1846 y 1870, para decaer luego frente al desarrollo químico de los tintes sintéticos (benceno y colorantes). Esa es, justamente, la cronología en que se consolidó la influencia de Francia, pues muchas de las familias francesas ligadas al comercio se establecieron en Santa Cruz de Tenerife atraídas no solo por la cochinilla, sino por otros productos de exportación, y propagaron, junto con otros ciudadanos franceses arraigados en esta capital, como el pintor Cirilo Truilhé o el gran estudioso de la cultura y la botánica, Sabino Berthelot, el prestigio de Francia, las excelencias comerciales de Marsella y el privilegio de estimarse ciudadano de París como facultad inherente a todo hombre moderno, civilizado y de espíritu burgués, independientemente de su lugar de nacimiento o residencia.

Bien es cierto que el desarrollo insular se propició por las especiales circunstancias políticas españolas que, por primera vez, y bajo el reinado de Isabel II, favorecían el progresivo incremento de las comunicaciones (ferrocarriles, carreteras) y un lento, pero gradual, proceso de industrialización, no exento de escándalos económicos, políticos y sociales, hasta el punto de producirse la revolución llamada La Gloriosa, en 1868, y la I República española, de corta vida (1873-1874). Pero, como es lógico, el hecho de mayor trascendencia fue la aprobación de la Ley de Puertos Francos de Canarias, redactada por el ministro Juan Bravo Murillo en $1852^{2}$ y aprobada por la reina. Esto significaba, en la práctica, la aplicación de algunos principios devenidos del estado de ánimo francés en la revolución burguesa de 1830, que impregnó muchas de las decisiones de la soberana española y sus gobiernos, entre ellas, la apertura de los puertos de Canarias, libres de aranceles, a la economía mundial. Gracias a esa libertad se favoreció el mencionado comercio de la cochinilla, pero, en esencia, se gestó un régimen diferenciado en lo económico y en lo cultural al resto del país, que agudizó la admiración por lo francés como sinónimo de moderno.

El arte no fue ajeno a esta situación. La revolución burguesa santacrucera, entendiendo como tal la construcción de una nueva cara visible de la ciudad

2 Una interesante glosa de su personalidad, acción política y decisiones económicas, como esta Ley, auspiciada por varios canarios ante la Corte, se debe a Coriolano Guimerá (1993: 41-53). 
portuaria y comercial, pasó por la construcción de un teatro y un mercado centrado en las mejoras higienistas del siglo, la edificación de un palacio para la representación del poder militar y la edificación de entidades que albergasen a las sociedades culturales y recreativas, como Santa Cecilia, proyectada en 1882 por el arquitecto Manuel de Oraá y Arcocha (1822-1889), un edificio profundamente clasicista (Fraga González 1999: 193-194) que en su fachaba tetrástila cubierta por un frontón pretendía mostrar el triunfo del saber. Pocos años después, en los inicios del siglo xx, se erguía el Templo Masónico de la logia Añaza 270, proyectado por Manuel de Cámara en 1900 con una fachada de extensa iconografía masónica que no se concluiría hasta 1923; de hecho, siguiendo a David Martín López, «se trata del primer edificio masónico creado ex profeso a modo de logia que exterioriza en fachada sus símbolos iniciáticos en España» (2009: 509).

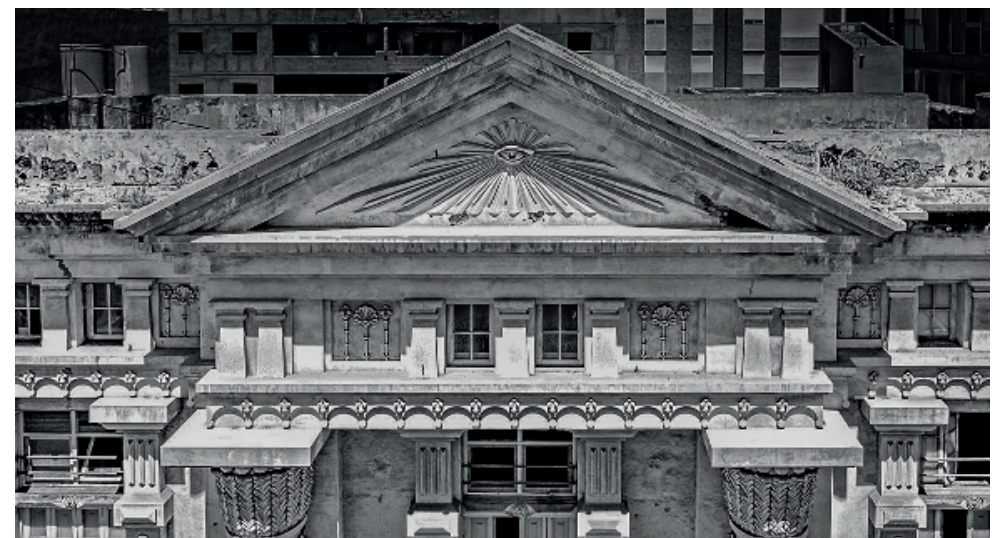

Fig. 1: Fachada del Templo Masónico de Santa Cruz de Tenerife (detalle del remate). Proyecto de Manuel de Cámara, 1900. Fotografía cortesía de Carlos Pallés Darias.

Todas las edificaciones señaladas, entre otras, crearon un perfil urbano y burgués que se sobreponía a las torres de iglesias y conventos del Antiguo Régimen. Como es natural, ese crecimiento artístico vino claramente estimulado por la creación en 1849 de la Academia de Bellas Artes, antecedente de la actual Real Academia Canaria de Bellas Artes de San Miguel Arcángel, que estimuló la aproximación de los jóvenes tinerfeños al ejercicio de las distintas técnicas. A ella se añade la Sociedad Económica de Amigos del País de Santa Cruz de Tenerife, que, aunque fundada en 1837, pronto decayó hasta su refundación en 1864, para acabar desapareciendo prácticamente en 1899. El Gabinete Instructivo se estableció en 1869 y fue muy activo hasta 1901 por la extraordinaria calidad cultural de sus socios. En ambos casos, no se trataba de sociedades estrictamente artísticas, pero sí humanísticas, pues sumaban al interés por la agricultura y el desarrollo canario, la divulgación de los estudios botánicos, zoológicos, sobre la cultura guanche y, cómo no, las artes plásticas, organizando varias exposiciones inspiradas en la idea de exposiciones universales, con una sección 
específica dedicada a las artes. El recorrido que Alejandro Cioranescu realiza por las instituciones culturales santacruceras del siglo XIX nos permite apreciar los esfuerzos que se materializaron en la erección de estos centros, aunque no siempre tuvieron continuidad por la falta de fondos (Cioranescu 1979: 224-227). Pero la ausencia de economía no debe menoscabar los esfuerzos por dotar a la ciudad de una continuidad en la organización de la cultura que provenía de la sociedad, no de las instituciones, un modelo inverso al que se ha construido desde la segunda mitad del siglo $\mathrm{xx}$.

Podemos concluir que el prestigio de Francia será indisociable del éxito de la sociedad burguesa santacrucera y su consideración por las artes; hemos advertido en la consulta de las fuentes originales que en la prensa local se citaba mucho más el nombre de París que el de Madrid; no se trata de una cuestión de índole política, sino de una evocación a la internacionalidad y la modernidad cultural, arribada a la Isla como consecuencia de la apertura de los puertos y del asentamiento de una numerosa colonia extranjera, notoriamente francesa, con gran capacidad de influencia sobre la sociedad local.

\section{El arte para una sociedad burguesa bajo la influencia de Francia}

El siglo XIX se inició con una personalidad artística que marcó la transición entre el Antiguo Régimen y lo que suponía la influencia francesa del Clasicismo y el primer Romanticismo. Se trata del pintor, nacido en el Puerto de la Cruz (Tenerife), Luis de la Cruz y Ríos (1776-1853), quien llegó a ser pintor honorario de cámara del rey Fernando VII entre 1815 y 1829. El autorretrato, pintado hacia 1829-1830, que ya hemos estudiado en trabajos anteriores (Castro Brunetto 2018: 152-153), lo muestra en ropas domésticas junto a un retrato recién pintado del monarca (un cuadro dentro del cuadro), revelándose en una actitud tan dandi como afrancesada. Esta osadía la entendemos como una manera de afianzar su papel como artista junto al monarca y, por lo tanto, mostrarse cercano ante el rey es una manifestación evidente de la nueva actitud burguesa. Nos interesa la personalidad de Luis de la Cruz porque, en la primera década del reinado de Isabel II (bajo la regencia de su madre, María Cristina de Borbón y del general Espartero) y hasta la fundación de la Academia de Bellas Artes, en 1849, era el pintor de referencia para los intelectuales canarios. En su biografía destacan éxitos en el entorno cortesano, algunos ligados a Francia, que le valieron condecoraciones galas. Su estilo afrancesado se advierte tanto en los retratos existentes en las Islas como en miniaturas y grabados llegados a Tenerife, dándole fama y popularidad entre las élites locales. Una prueba es el retrato doble, pintado en 1832, de los reyes Fernando y María Cristina que se conserva en el Museo de Asturias, cuya factura anuncia el sentido romántico del arte de Luis de la Cruz (Rumeu de Armas 1997: 104-107). Pero el hecho que nos interesa especialmente en este trabajo es que, cuando la Academia de Bellas Artes tinerfeña deseó dar un halo de prestigio a su flamante centro docente, buscó la presencia del pintor de corte entre su cuerpo docente, lo nombró, en 1850, socio de honor 
y, en 1852, le entregó una cátedra mientras aún residía en Málaga, que el pintor aceptó, aunque no pudo incorporarse, pues murió en Antequera al año siguiente (Rumeu de Armas 1997: 177).

La formación artística organizada en torno a criterios concretos se había iniciado en Tenerife al crearse en La Laguna en 1786 la escuela de dibujo del Consulado del Mar, cuya actividad más importante se había consolidado en los primeros años del siglo XIX con la presencia del mencionado Luis de la Cruz, y que atravesaría altibajos que la llevarían casi a extinguirse conforme avanzaba el siglo. Será en 1846 cuando el entusiasta ingeniero y arquitecto santacrucero, pero de origen francés, Pedro Maffiotte Arocha (18161870), contando con la colaboración de jóvenes pintores como Nicolás Alfaro y Brieva (1826-1905) y el estímulo de Sabino Berthelot, agente

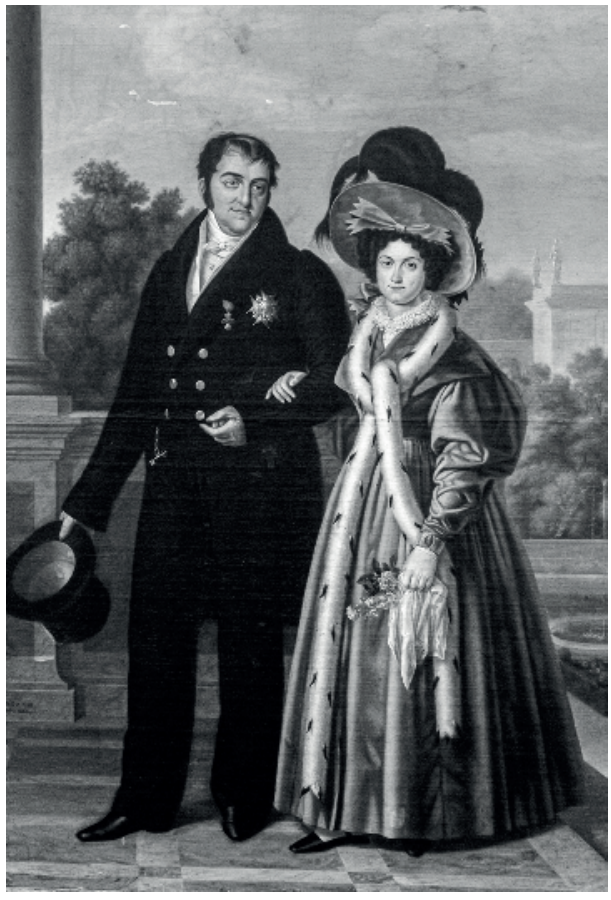

Fig. 2: Retrato de Fernando VII y María Cristina. Óleo sobre lienzo, Luis de la Cruz y Ríos, 1832. Museo de Bellas Artes de Asturias. Fotografía Carlos Javier Castro Brunetto. consular de Francia desde el año 1847, estableció la Sociedad de Bellas Artes, que funcionaría durante casi tres años, y que significaría un momento pregnante del arte en Canarias por la trascendencia que tendría años después (Martínez de la Peña, Rodríguez y Alloza 1987: 27-33). Se ofertaba en dicha Sociedad clases de pintura, dibujo y escultura, a las que se sumaron las de música y arquitectura; pero lo más importante fue la decisión de mostrar los avances de los alumnos en exposiciones, que se celebraron en 1848, 1849 y 1850. Aunque no parezca especialmente relevante, significó una verdadera revolución, porque evidenció un nuevo orden presidido por la exhibición al público de las creaciones; con ello, la sociedad santacrucera reafirmaba el sentido público y popular del arte como una parte innegable de la educación de la sociedad burguesa.

Mientras se extinguía la Sociedad de Bellas Artes, por Real Decreto de 31 de octubre de 1849, se creaba, junto a doce academias más en toda España, la Academia Canaria de Bellas Artes (futura RACBA), centro de formación oficial en las artes de la pintura, dibujo y escultura, que tenía como marco de acción la provincia de Canarias. Fueron profesores, entre otros, algunos de los pintores y escultores introductores de la tradición clásica o del Romanticismo, como el pintor Lorenzo Pastor y Castro (1784-1860), su primer presidente, el escultor e imaginero Fernando Estévez (1788-1854) y artistas de una generación más 
joven, como Nicolás Alfaro (1826-1905) (Siemens 2013: 11-12). Pedro Maffiotte asumió la impartición de nociones sobre arquitectura y Sabino Berthelot, desde los bastidores, actuó como catalizador de la relación entre las artes y la sociedad, bajo la impronta francesa en el sentido estético del arte, sugiriendo los dibujos de estudio y paisaje al natural. Con ello incentivó, tal vez sin proponérselo, lo que se denominará en la década de 1860 como pintura al plein air.

La prensa dejó noticias relevantes sobre los primeros pasos de esta institución. En el acta de la Sesión de la Academia Provincial de Bellas Artes, reunida el 19 de noviembre de 1852, presidida por Lorenzo Tolosa, el secretario, otro francés, Bartolomé Saurin, expone que, desde su fundación en 1849, la Academia solicitó a la reina que se estableciesen estudios de armas, marina, ingeniería, etc., ya que eran pocas las familias que podían sufragar el envío de sus hijos fuera de Canarias a cursarlas, y que, además, la miseria obligaba a los insulares a emigrar a las Antillas. Pero afirmaba que, temerosa de que estas solicitudes no fuesen atendidas, la Academia se conformaba con que se mantuviesen las gracias ya concedidas de clases de dibujo del antiguo y natural, y de pintura (El Noticioso de Canarias 24/11/1852: 3-4).

Para entender el contenido de las exposiciones y la evolución de las artes, nos parece interesante la crónica de la sesión de la Academia que se celebró en enero de 1856, en la que se ponderaba que, pese a su reciente creación, gracias al ánimo de unos pocos entusiastas, se hubiese llegado a tan buenos resultados en la creación artística:

Sus retratos eran de una verdad asombrosa y sus hermosos paisajes tomados de los puntos más pintorescos de las islas [...]. En cuanto a las obras de las Srtas. Jacobina Bello y Herminia Armas diremos que hemos notado mucho adelanto en ellas y que los medios están a su alcance para avanzar en la delicada senda que han emprendido [...]. En cuanto a los buenos cuadros que nos ha remitido el Sr. León, artista de la Ciudad de Las Palmas, nos llamó mucho la atención una copia del sacamuelas de uno de nuestros afamados pintores, el lienzo que representa un perro y un pequeño Teniers (si no nos equivocamos) [Y refiriéndose a lo que denomina jóvenes artistas] Basta que consignemos aquí que en general notamos adelantos y que el Sr. de Robaina en sus cuadros de composición y algunos retratos descubre a primera vista el genio que le anima y la gran facilidad con la que maneja el lápiz y el pincel, buen testigo es de ello su copia de una de las Concepciones de Murillo. Buen colorido y gran semejanza notamos en los retratos del Sr. Truilhé y le damos la enhorabuena por su cuadro de la aldeana que contempla un cántaro roto. Hay mucha expresión y poesía en ese lienzo [...] (Eco del Comercio 12/01/1856: 1).

Es interesante que el periódico destacase la presencia destacada de mujeres, como la británica Elizabeth Murray (1815-1882), residente en Tenerife entre 1850-1859, y de Solita Diston, hija del también inglés (y dibujante) Alfred Diston, afincado en el Puerto de la Cruz y discípula de Elizabeth ${ }^{3}$. También

3 Lo más revelador sobre la artista es su propia obra, estudiada por José Luis García Pérez, publicada bajo el título Recuerdos de Tenerife. 
se exhibieron obras de Jacobina Bello, y otras mujeres pintoras, estudiadas por Carmen Fraga (2018: 45-54). Estas investigaciones reconocen en el cónsul francés Sabino Berthelot a la figura mediadora para que el arte hecho por mujeres también entrase en la vida cultural santacrucera.

El freno causado por el cierre de la Academia en 1869, con motivo del proceso revolucionario, y su ausencia hasta ser restaurada en 1913, sumieron a la capital de Canarias en un cierto caos que solo fue suplido por la escuela municipal de dibujo de Santa Cruz y la creación del Gabinete Instructivo, ambas instituciones formadas por prohombres guiados por el impulso de modernizar la ciudad y las Islas en su conjunto. Las artes continuaron desempeñando un papel predominante, y esto lo vemos en la convocatoria de nuevas exposiciones. Entre ellas, la de 1883. Ortiguilla, seudónimo de Luis Maffiotte La Roche (su hermano Juan firmaba como «Licenciado Ortigas»), componía la siguiente crónica de la muestra promovida por la Sociedad de Bellas Artes (se refiere a la escuela de dibujo):

Bonitas, delicadas y numerosas eran las acuarelas de L'Allier y de Tarquis: ya conocemos a estos dos artistas y guardamos los elogios que de ellos pudiéramos hacer para sus cuadros al óleo. Valera (D. Federico), presentó una fotografía iluminada con tal gusto que encantó a los que la vieron. La delicadeza, sobre todo, llamaba mucho la atención. Son ya viejos en el arte Truilhé y Robayna, y por eso no podemos aconsejarles perseverancia en el estudio: si tienen algunos defectos, con ellos seguirán siempre; en cambio no perderán tampoco sus buenas cualidades. De Bello y Meléndez no vimos nada. Baeza presentó dos cuadritos tomados del natural y un estudio de perspectiva. Está tan bien representado el natural que, francamente, quisiéramos más fantasía, más inventiva en el pintor [...] (La Ilustración de Canarias 15/01/1883: 8).

En 1891, el Gabinete Instructivo fomentaba las artes con un perfil mucho más amplio, porque a los géneros pictóricos se sumaban las artes decorativas, una visión cada vez más realista y aproximada al gusto del final del siglo, alimentada de forma notoria por las exposiciones universales celebradas en Francia e Inglaterra, que sumaban con igual entusiasmo la pintura a la decoración.

Bello (Ana), Un retrato (óleo) y flores sobre raso (óleo) [...] Bordoy (Francisca) dos pañuelos bordados [...] Cámara (Don Manuel) Dos proyectos de casas consistoriales [...] Corsa (Diego) Un plato, dos acuarelas, una cabeza de estudio y un paisaje al óleo y una fotografía iluminada [...], Gondrán (Pilar) tres cuadros al óleo, tres dibujos al creyón, una cartera bordada, González Méndez, una acuarela, Lallier ocho paisajes y dos platos al óleo y una acuarela, López de Vergara (Arturo) Una acuarela [...], Robayna (Gumersindo), dos cuadritos y un retrato al óleo, Robayna (Teodomiro) dos tipos españoles, dos tipos del país, un retrato, un capricho y un plato (óleos) [...], Tarquis (Pedro) cuatro cuadros al óleo, uno al pastel, dos dibujos a la pluma (copias de Goya) y dos platos al óleo [...] (Diario de Tenerife 13/07/1891: 2).

Una exposición verdaderamente apoteósica fue la organizada por la Sociedad Económica de Amigos del País en la sede del flamante y clasicista edificio de la Sociedad Filarmónica Santa Cecilia, construido entre 1883 y 1887 por el 
Año XII-Segunda ép̉oca

ISLAS CANARIAS

Nưm. 835

\begin{tabular}{|c|}
\hline 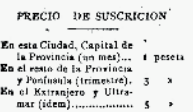 \\
\hline
\end{tabular}

PERIÓDICO LIBERAL-CONSERVADOR

Santa Cruz de Tenerife 5 de Mayo de 1892

\section{LAS FIESTAS DE MAYO}

\section{PRELIMINARES}

Oporlunaments publicatnos el prograna yus la jumta organizzdora de que nuestros abonados tuviesen por hahina de verittcarse los festejoy.
Testos batu tenido lugar con arreglo

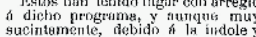
dimensiones de unestro pariódico y la premura del liempo, vamos a dar
de cllos cuenta. Movimieato desusado so notnbe ca
as callns de nuestra Capityl en to diss anleriores al comienzo de las paso por lis calles de lis que cou-

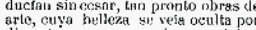
disirete gasa, corno primorosa labor en la que los dedos de alguna bell digno de las hadas; los cnurma eestones de botellas que por sus eti-
quetos Hardisaon, Hamiltom, Fornon-

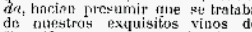
T'enerife, Y que ersan conducidos an de aceite, los trabajos típográticos. las clegantes envolturas del más
cequisito tahaco del pais; tudo esto que por celles y plozas se reia crula solemnidyd cue so prepuribion era de esas exposiciones vulgares que tan í mentido tienen lugar el

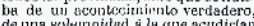

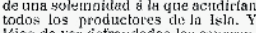

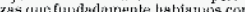
cebitu, tenemos que coufespr, con orgullo legitimo para Teuerife, \& lue se

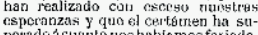
peradoácucuatontonos habiamos forjado. Pero, para "o involucror ideas,
conveniente es proceder cou cierly convenieute es proceder con cierlo
orden y para ello el mejor es el crono
logico.

Er. Muet.r.e.-Akios.- Adohisos Fv vaRLAS CAEAS.

Magico cra el ctecto que of muelle prescitaba; coll sus inuubier'ables das nacionsles, que flotabau nl viesto Juciendo los colores de la mentire pa-
triá; el arco de tres cuerpos en extreind eleganle y los sidurnos gue osten-

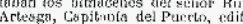
cio de ta Sotidad y Peserderiy, cau-
silar verdadoro inatusiasmo aj mós silai verdadoro bahasiasmo af mós
exigente.

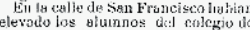
2," cuseñatiza que tau digngment urci lurmatic por esbettos columants

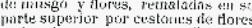
y dos tuisparebtes con al tributos de

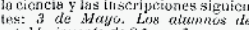

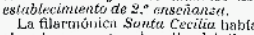
tillo, cosi in las puertas del local th la sociedad: bolas suciltus, pentígre-

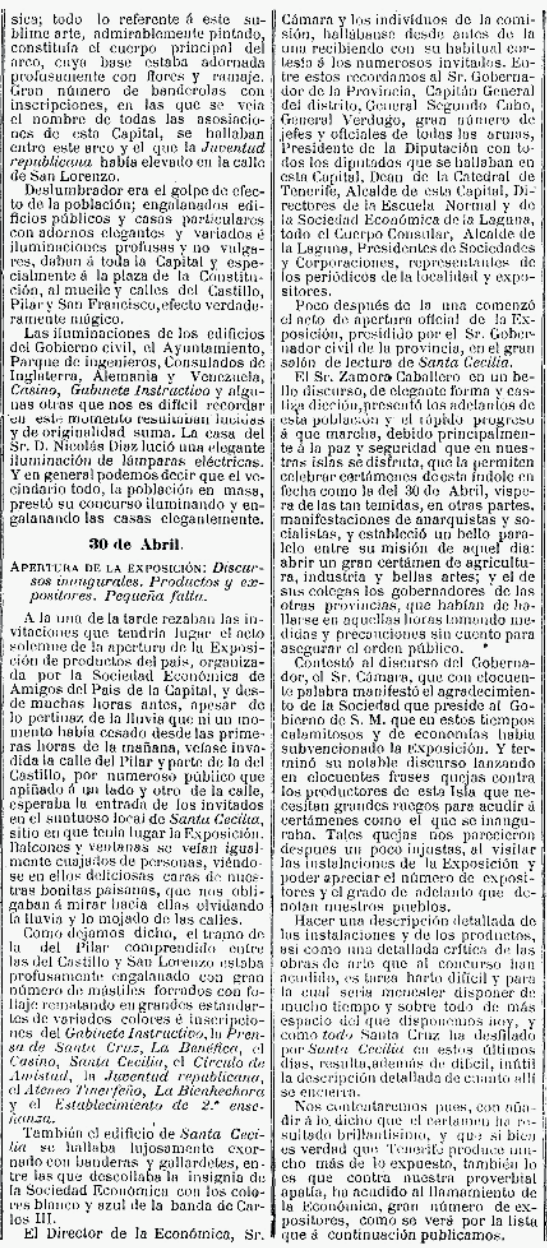

A las tres proximanen le abantonemos el locol los invitados, despues expléndifor refresen, en quie los senigres de laj junla hiciorin ios hovore. IIe aquif, por orden alfabetico, ia que prescitaz:

PRIMPIZA SECCÓN

Bellas Aries $y$ PHMAER GRT'TO

Alquarex Gonzillez (D. Terancisco) Un dibujo

is lis plums.
Basulet Matión (D. Dámano) 2 ouadrón

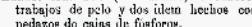
Bonnin (D. Francisco) Dos cuadroa ş pn plato al oleo y nan acrarela.
Bordsoova (1), Ubaldo) Dos cuedroe al ólco,

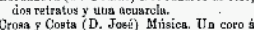
voces solas y 7 piezas de haile.
Cartu (D. Mfiguel)' $\mathrm{Ca}$ enudo tallado (bajo Gondrán (Srita. D.* Emelias) Da dibajo al Gregón. (1). Filar) Trea retratos al titeo. Goodrua (D). Pilar) Trea retratos al iteo.
Gouzílez Perers (D. Pedro) Dos cuadros al carbóa. Gouź́lez. Méndex (D. Masuel) Tres cradros de gívero $y$ trea retratos al aleo.
(traigou (D. Franeicco) Una obra musical Guiyou (D. Francieco) Una obta musital Morales y Real (D. Masuel) Un plano topogrúfícn al lasado.
Peúa (D. Francibco J. de la) Un ouadro al óleas res, alegoria del Qujijote y dos paisajes a óleo.
Todrigues (D. Felipe) Dog cusdros al ólea, 1 acuarela $g$ apuates sl lápiziz.
Romero (D. Angel C.) Una instalación coll trakspios litourrificos.
Romero y Mateos (D. Augel) Lin retrato pranedimiento litugráfico lito-gelatipa.

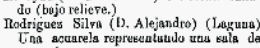
Sauz (D. Vialentin) Quatro ouadroo al doloo.

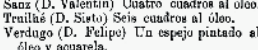
cles y acuarela. Buker (b. Carlos .I.) lin perro direoado. Carts
Caudelaria y Memoris deseriptiva de lo mistua.
Porunds (D. Pedro) Mfueatras de produrtos mineralas. Oberas Publicas (OGicinse de) ejemplares de las casterius de Tenerite.
Pérez Abreu (D. Manuul) (Snats Craz de io

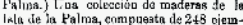
Sulures. piedrs basillica purs coustracion (de re
jina.) Wilpret (D. Germin) (Orotara) Butubas vol. ejnicsy del Tejde y Arato.
SEG UNDDA SECorion EGXNDA SECCION Agricultura
rebreth eaury Srmovo (1). Simán) Minestras de remoluchas Carta (D. Juad P.) Muestras de eafie

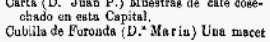

Fig. 3: Exposición de la Sociedad Económica de Amigos del País de S/C Tenerife en la Sociedad Santa Cecilia, abril de 1892. Diario de Tenerife, 5 de mayo de 1892, p. 1. Extraída del buscador Jable (ULPGC), dominio público. 
arquitecto municipal Manuel de Oraá y Arcocha, como ya hemos indicado. El 30 de abril de 1892 se decidió realizar dicha muestra con un despliegue ornamental en la calle del Pilar (tramo que en la actualidad denominamos Teobaldo Power), en frente de la fachada de la Sociedad. En sus salones, siguiendo los principios de las exposiciones universales, pero a escala local, se organizaron en secciones las novedades en los campos de la agricultura, minerales, animales disecados, etc., también la de bellas artes. Veamos parte del resultado:

El tramo de la calle del Pilar comprendido entre las del Castillo y San Lorenzo estaba profusamente engalanado con gran número de mástiles forrados rematado en grandes estandartes de variados colores e inscripciones de El Gabinete Instructivo, la Prensa de Santa Cruz, la Benéfica, el Casino, Santa Cecilia, el Círculo de Amistad, la Juventud Republicana, el Ateneo Tinerfeño, la Bienhechora y el Establecimiento de $2^{a}$ enseñanza [...]. Entre los expositores [selección] se hallaban D. Dámaso Baudet Martinón con dos cuadros trabajo de pelo y dos idem hechos con pedazos de cajas de fósforos, D. Francisco Bonnín con dos cuadros y un plato al óleo y una acuarela, D. Ubaldo Bordanova con dos cuadros al óleo, dos retratos y una acuarela, D. José Crosa y Costa con música, un coro a voces solas y 7 piezas de baile [...], Da Pilar Gondrán con tres retratos al óleo, D. Manuel González Méndez tres cuadros de género y tres retratos al óleo, Don Ángel Romero Mateos con un retrato proceso litográfico lito-gelatina, D. Gumersindo Robayna con un escudo tallado (bajorrelieve), D. Valentín Sanz cuatro cuadros al óleo, D. Sixto Truilhé con seis cuadros al óleo, D. Felipe Verdugo, un espejo pintado al óleo y acuarela [...] (La Opinión 05/05/1892: 1).

Durante la década de 1890, la actividad desarrollada por la Sociedad de Amigos del País continuó siendo muy intensa e, insistimos, el estímulo no eran ya las ideas ilustradas divulgadas por este tipo de instituciones, sino el propósito de extender las novedades presentadas en el campo de la industria y las artes propaladas en las exposiciones universales, especialmente en el caso las exposiciones celebradas en Francia, entre las personas interesadas, los próceres tinerfeños. De similar interés es el reporte de las medallas otorgadas en la exposición correspondiente a 1894:

[...] En medalla de segunda clase Cirilo Truilhé por paisaje al óleo, José Ravina por un paisaje al óleo, Manuel Picar (Laguna) por un jarrón decorativo, Joaquín Estremera por un relieve en barro cocido, Marcos Baeza (Puerto de la Cruz) por un paisaje al óleo [...], de segunda clase Gumersindo Robayna por una escultura, Diego Crosa y Costa por acuarelas, Francisco Bonnín y Guerín, varios cuadros al óleo y acuarelas, carta de aprecio, Lía Tavío (Puerto de la Cruz) por dos cuadros al creyón, y otros [...] (Diario de Tenerife 11/06/1894: 2).

Una lectura atenta de este tipo de noticias es útil, además, para advertir los cambios generacionales; por ejemplo, junto a los maestros, aparecen citados los nombres de Diego Crosa, Francisco Bonnín y Lía Tavío, que ocuparían papeles relevantes en el desarrollo de la cultura canaria del futuro siglo.

Otra forma de valorar el prestigio de Francia en la segunda mitad del siglo XIX es la observación del tipo de objetos que se comerciaban, los bienes de consumo doméstico y, como es lógico, la publicidad. La moda, como lenguaje 
de la sociedad burguesa, se abre paso durante este tiempo con gran fuerza. Esencialmente, es un lenguaje de comunicación por el que la sociedad comparte una identidad colectiva y, con ello, alcanza, al mismo tiempo, modernidad y sosiego al confundirse entre la masa. Pero también sucede todo lo contrario, es decir, que a través de la moda se busca un lenguaje personal e irrepetible por medio de textiles o complementos, aunque a veces es tal la originalidad, que provoca en muchos el deleite de la imitación, reiniciándose el ciclo de la moda como valor de consumo, para disgusto de los originales. Pero no pretendemos en estas líneas establecer un análisis sobre el impacto de la moda en la cultura, sino reflexionar sobre la autoridad de Francia en esta materia. La prensa tinerfeña está atravesada a lo largo de esas décadas por las referencias a las sederías de Lyon, las fábricas de paños del norte de Francia y los diseños de París. Nadie que fuese considerado elegante lo sería sin referirse a París en la construcción de su imagen visual, a partir de los figurines que llegaban a Tenerife a través de las revistas madrileñas de moda, que recogían noticias e imágenes provenientes de las revistas francesas, al mismo tiempo que todos los comerciantes de textiles apuntaban al origen francés de la calidad de las telas vendidas o de los cortes de ropa de confección.

En 1848, la prensa tinerfeña se hacía eco de las novedades en los modernos fracs de los caballeros en el viejo hipódromo parisino de Longchamp:

[...] El frac se lleva abrochado con una sola hilera de botones que lo cierra desde la cintura al pecho, dejando una pequeña vuelta en la solapa; el talle es más alto que los que hasta ahora se han usado, aunque siempre debe bajar dos pulgadas de la cintura; el faldón debe estar recortado un poco a la unión del cuerpo dejando una mella como en el traje de etiqueta; debiendo tanto unos como otro, estar muy redondeados y sin bolsillo en el pecho. Las levitas deben cruzar un poco y llevar dos hileras de botones, pero muy juntas, la falda corta y de mediano vuelo, aunque las de paño y seda fuertes empiezan a desterrar a aquellas con su preponderancia [...] (El Eco de la Juventud 15/05/1848: 6).

Otro ejemplo, en este caso de 1857 y referido a la mujer, lo encontramos en el periódico santacrucero El Instructor y el Recreo de las Damas, concebido para el público femenino, que destacaba la observancia del modelo de mujer francesa como el más atinado para la tinerfeña:

Los periódicos y figurines de modas que acabamos de recibir de París, corresponden al mes de noviembre último [...] Para los sombreros se estilan diversos adornos y prendidos de suma elegancia y gusto a juzgar por los siguientes. Un prendido romano, compuesto de una redecilla de oro, cayendo en forma de bucle flexible y hueco sobre la nuca [...]. Los figurines contienen las novedades siguientes. Vestido de glasé liso guarnecido con botones de terciopelo negro. Mantón de terciopelo negro adornado con una tira ancha de terciopelo escocés y un fleco con pie de encaje. [...]. Vestido a cuadros de dos colores con enaguas sin adornos. Manteleta guarnecida con un fleco que se coloca sobre la misma tela [...] (El Instructor y el Recreo de las Damas 20/12/1857: 1-2).

Los comercios más populares de la ciudad anunciaban la venta de productos franceses destinados a la moda. En 1858, en el establecimiento de D. Faustino 
de Armas «se acaban de recibir de Francia por el buque Patriarque un magnífico surtido de ternos y pantalones de superior calidad, charoles, becerrillos, flores artificiales, sombreros adornados para montar [...] sombreros de felpa para caballeros, badanas, delanteras bordadas para camisas [...] vestidos de seda con volantes, sobreros de paja para niños [...]» (Eco del Comercio 25/09/1858: 3). Pocos años después, como simple testimonio, en el almacén Valle de Taoro, sito en calle del Castillo n. ${ }^{\circ} 22$, se informaba de la recepción por los vapores Tharsis y Pelayo, procedente de las mejores fábricas de París, Lyon y Marsella, de un surtido de vestidos de seda negra y colores, gorras para señora, terciopelo negro, sombrillas, corsés, miriñaques, cinturones, sobretodos de seda bordados, sombreros de pelo, cachorras a la moda de París, etc. (Eco del Comercio 24/02/1864: 4). En 1868, el almacén de paños de José María Palazón, calle del Castillo n. ${ }^{\circ} 21$, anunció que los tejidos que vendía provenían de las mejores fábricas de París: cachemires de última moda, satenes y paños negros, bayetas de todas clases, tartanes para forros, y otras mercancías (El Insular 29/07/1868: 1).

La moda también se asociaba, hasta adentrado el siglo $\mathrm{xx}$, con el consumo de productos de alimentación franceses, considerados gourmet. En 1860, el comercio La Barcelonesa: efectos españoles y extranjeros, anunciaba la llegada desde Marsella de un «precioso surtido de sombreros de liorna para niños, sombreros de pelo para caballeros [...] sopa fina, champagne, coñac y una diversidad de licores [...]» (Eco del Comercio 14/01/1860: 4). Al año siguiente, la misma tienda confirmaba haber recibido, por el vapor Marocain, zapatos y cachuchas [boinas] para niños, sardinas de Nantes, champagne, cerveza y otros licores, cortes de pantalones, cortes de chalecos, de seda y felpa, etc. (Eco del Comercio 21/09/1861: 4).

Como simple curiosidad, la Exposición Universal de París de 1889, que conmemoraba el centenario de la revolución francesa, se inauguró el 6 de mayo, y uno de los acontecimientos fue la presentación de la torre Eiffel, símbolo del evento. Cuál sería su rápida popularidad que, en la tómbola benéfica organizada ese año, se anunciaba el 26 de junio que «Don Ernesto Guimerá [dona] una polvera de nikel representando la torre Eiffel y dos muñecas de cera» (Diario de Tenerife 26/06/1889: 2).

Estos son solo algunos ejemplos de una breve muestra de la reputación de Francia. Por todo ello, en la sociedad tinerfeña se instauró un nuevo orden, donde el concepto de arte quedaría asociado a la

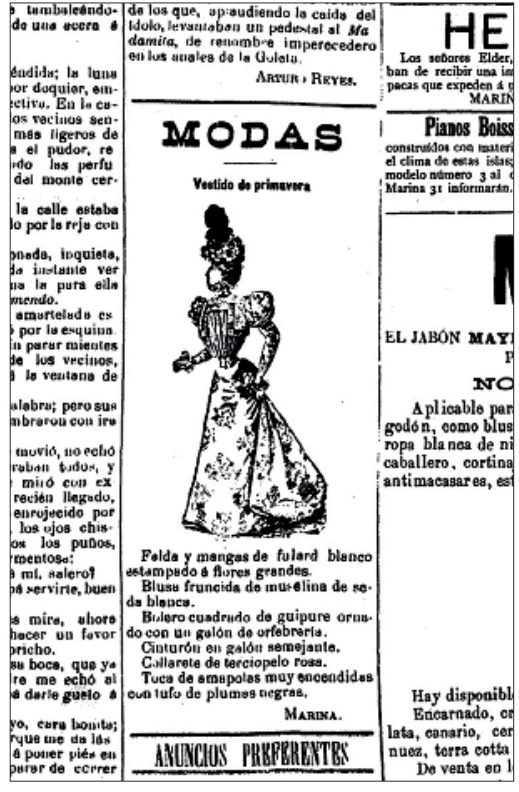

Fig. 4: Anuncio modas de primavera. Diario Tenerife 15 de mayo de 1897, p. 3. Extraída del buscador Jable (ULPGC), dominio público. 
excelencia. La organización burguesa en sociedades culturales, el progresivo disfrute de las artes, de la moda o el sibaritismo, tendría en Francia su referencia más notable. Detrás de las exposiciones había una sutil imitación de las exposiciones universales, detrás de la pintura, un deseo por llegar a la cumbre romántica que representaba la vida intelectual parisina, detrás de las relaciones sociales, la aspiración a disfrutar de una vida elegante, a la moda, que asemejen los escenarios santacruceros a los franceses.

\section{La estética francesa en Tenerife}

La percepción de la belleza moldeada por pintores y teóricos en París durante la segunda mitad del siglo xIX estimuló un espíritu crítico y, por tanto, estético, que atrajo a los intelectuales de todos los puntos de Europa hacia Francia. Son innumerables las publicaciones sobre esta cuestión, desde estudios generales como el clásico de Rosenblum y Janson (1992), que enfrenta el francocentrismo con la evolución de los ideales estéticos como fenómeno universal, hasta análisis concretos, como el papel de los artistas en la sociedad francesa, planteado por Ferrer Álvarez (2014). Por ese motivo, no pretendemos aportar novedades al respecto, sino hacer notar que la estética francesa forjó moldeó el espíritu de los artistas canarios, tanto por la influencia venida del exterior, por medio de personas u objetos artísticos, como por el viaje a Francia de los artistas nacidos en Canarias. Bajo esta perspectiva, Francia no solo aportaba prestigio: lo aportaba todo. Y fueron muchos artistas tinerfeños los que protagonizaron este afianzamiento de la estética francesa, además de asentar los principios fundamentales del arte del siglo xIx, tal como ha analizado y sistematizado María de los Reyes Hernández Socorro (1998: 39-65).

Es el caso de Cirilo Truilhé Hernández, aunque nacido y muerto en Santa Cruz de Tenerife (1813-1904), procedía de una familia francesa asentada en Santa Cruz, estudió pintura con Lorenzo Pastor y Castro y marchó a perfeccionar su instrucción en Burdeos, de donde regresó en 1835 con un bagaje trascendental: la relación del paisaje frondoso y literario, propio del Romanticismo francés, con la inclusión de figuras de la tierra, es decir, la inclusión del mago canario vestido con indumentarias populares. La preocupación por el sentido dramático y trascendente del paisaje renovó la pintura tinerfeña, y canaria en general, pues, hasta entonces, el retrato era el género por excelencia en las Islas. En realidad, seguiría siéndolo y Truilhé, uno de sus mayores cultivadores, pero el concepto de paisaje con figuras, tan francés, abrirá el camino a los grandes paisajistas realistas de la segunda mitad del siglo, como Nicolás Alfaro y Valentín Sanz.

Lo que estimamos en esta publicación es el impacto social de ese afrancesamiento de la pintura. La inclusión de Cirilo Truilhé como referente de la vida santacrucera es ampliamente recogida por la prensa y las monografías publicadas sobre él; valoramos el extenso estudio que le ha dedicado Carmen Fraga, quien lo relaciona con el concepto de libertad romántica que sobrepone la sensibilidad cromática y visual del artista sobre la copia del natural (Fraga 


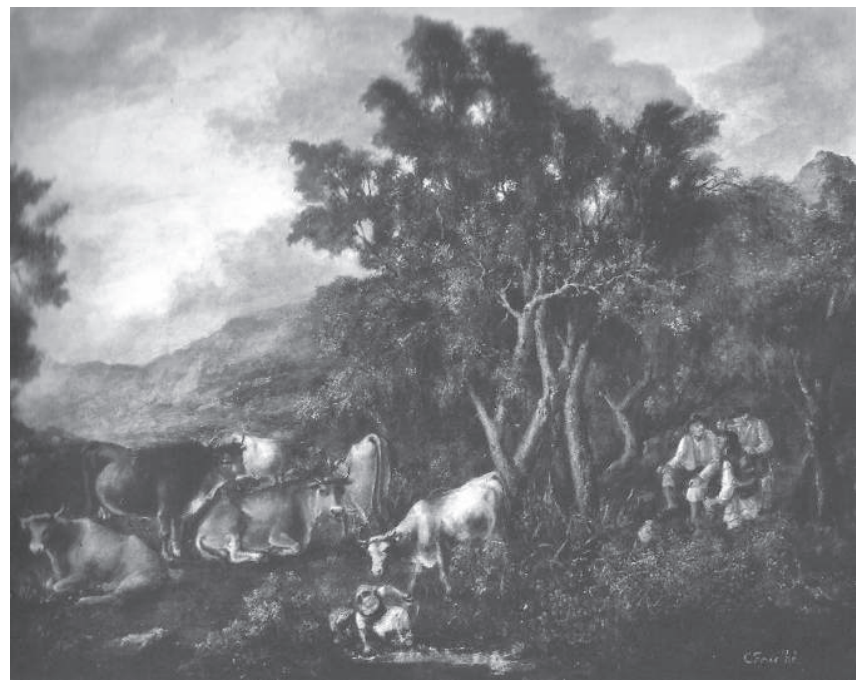

Fig. 5: Paisaje con magos y vacas. Óleo sobre lienzo, Cirilo Truilhé, c. 1854. Museo Municipal de Bellas Artes de Santa Cruz de Tenerife. Fotografía del autor.

González, 2013: 139). Pintó el retrato del músico francés Carlos Guigou (17961851), natural de Orange y llegado a Tenerife en la década de 1830 camino de la corte imperial del Brasil, en Río de Janeiro. Aquí se afincó y en la década de 1840 fundó una academia musical con una pequeña orquesta, siendo la primera institución considerable de la capital canaria. Tras su muerte, en 1852, se reanudan los conciertos en el teatro bajo la dirección de Matías Guigou, y, hasta 1853, se habían organizado siete. Será en ese momento cuando se decida encargar un cuadro del músico, encomendado al pintor más consagrado del momento, el también medio francés, Cirilo Truilhé (Eco del Comercio 31/12/1853: 3), hoy en colección particular. Participó en la exposición de la Sociedad de Bellas Artes de Santa Cruz en 1856 con un cuadro al gusto del Romanticismo francés: «le damos la enhorabuena por su cuadro de la aldeana que contempla un cántaro roto. Hay mucha expresión y poesía en ese lienzo [...]» (Eco del Comercio 12/01/1856: 1). Un año después, la prensa de Santa Cruz destaca el carácter benéfico del pintor por haber colaborado en el enriquecimiento del hospital de la ciudad:

[...] Bien desearíamos que nuestros jóvenes artistas, imitando el desprendimiento del Sr. Truilhé que en el año anterior donó al Hospital los retratos de sus fundadores, se presentaran a hermosear las salas y galerías del mismo edificio con obras alusivas a aquel piadoso asilo (Eco del Comercio 14/05/1857: 1).

En los años sesenta y setenta, Truilhé continuó pintando e innovando en el campo del paisaje, con mayor aproximación al detalle, aunque sin abandonar la figura; por ello, en su estudio sobre los pintores canarios del siglo XIX, Miguel Ángel Alloza lo define así: "Truilhé, con su espíritu romántico, se extasiaba cuando caía la tarde y la atmósfera envolvía tenuemente las formas del campo. Utilizaba la luz con maestría, logrando tonalidades cromáticas que daban en 
conjunto un sorprendente efecto» (1981: 300). El sentido estético de la pintura de Truilhé fue, por tanto, conceptualmente francés hasta el final; este hecho queda reforzado al ser el maestro del gran paisajista del último cuarto del siglo: Valentín Sanz.

Si Truilhé abrió caminos al gusto pictórico francés, Gumersindo Robayna Lazo consolidó esta trayectoria. Natural de Santa Cruz de Tenerife (18291898), se formó con Lorenzo Pastor y Castro. En 1852, y según recogió la prensa santacrucera, se desplazó para ampliar sus conocimientos en arte por las dificultades de hacerlo en su tierra natal:

En el místico Buen Mozo se ha embarcado para Cádiz el apreciable joven don Gumersindo Robayna, uno de los alumnos más aventajados de nuestra Academia de dibujo. El objeto del viaje es continuar, bajo la dirección de distinguidos profesores, y a la vista de las obras que encierras nuestros museos nacionales, el estudio de la pintura, a que se dedicó sin otros modelos ni dirección que las inspiraciones de su genio artístico. Esperamos tener la satisfacción de verle regresar a su patria para enriquecerla con la posesión de su perfeccionado genio tan aventajado como modesto (El Noticiosos de Canarias 14/07/1852: 3).

Realizó su formación fuera de Canarias entre 1852 y 1854 en Sevilla y Madrid, visitando los museos, en contacto con maestros de la pintura de ambas ciudades y participando de tertulias, hasta que finalmente llegó a París. Allí se familiarizó con los géneros del Romanticismo y entró en contacto con el efervescente entorno cultural, donde la pintura de historia y el compromiso político del arte se imponían como las grandes tendencias francesas frente a los cuadros mucho más dramáticos de los pintores alemanes e ingleses. Sin embargo, la enfermedad y muerte de su padre le hizo regresar a Tenerife, aunque no sin impregnarse antes del espíritu artístico galo, especialmente interesado por el retrato con grandes dosis de realismo.

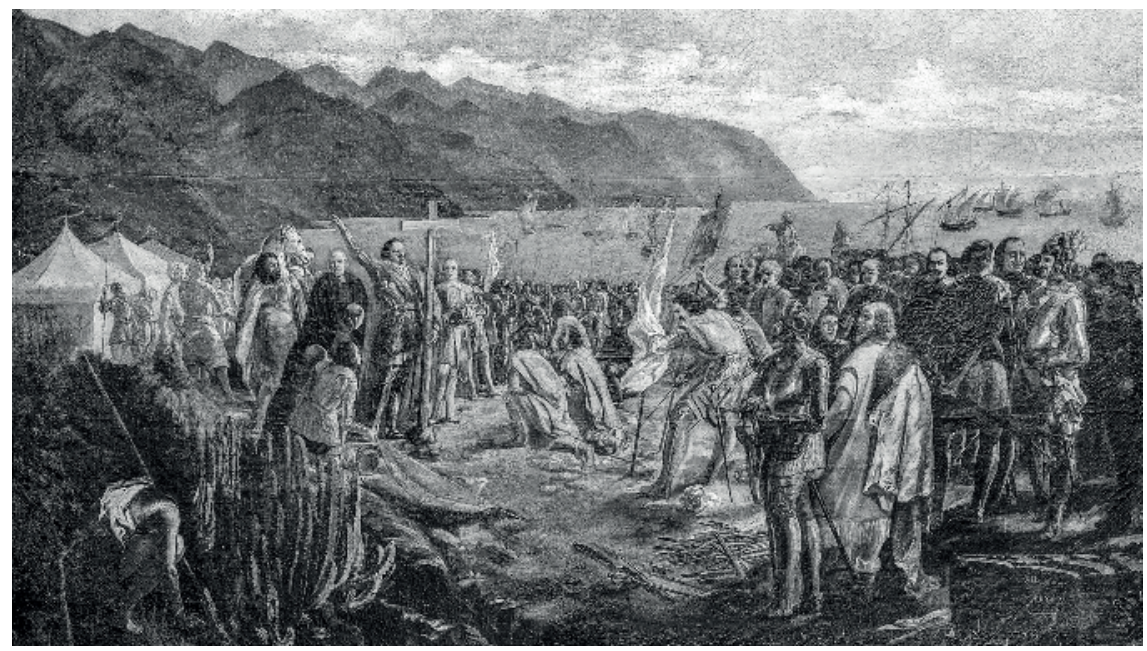

Fig. 6: Fundación de Santa Cruz de Tenerife. Óleo sobre lienzo, Gumersindo Robayna, 1854. Museo Municipal de Bellas Artes de Santa Cruz de Tenerife. Fotografía del autor. 
El aura francesa, además de los orígenes familiares, le permitió acceder al entorno privilegiado del arte local y, en una exposición organizada en 1854 por la Junta de Comercio, presentó un lienzo sobre el desembarco de Alonso Fernández de Lugo en Santa Cruz de Tenerife (Alloza Moreno 1981: 247), inaugurando la pintura de historia como género del Romanticismo francés aplicado a la memoria de Canarias. A partir de entonces, su influencia en la sociedad tinerfeña fue trascendental y se transformó en el prohombre de la pintura, tal vez a la altura del naturalista Sabino Berthelot. Se podría realizar una extensa memoria que demostrase la relevancia de su obra, siempre bajo el gusto francés, pero un lienzo en paradero desconocido (Fraga González 1993: 18), si es que aún se conserva, es la obra cumbre bajo esta perspectiva. Robayna fue un republicano convencido y, como tal, vivió intensamente la proclamación de la Revolución de 1868, de tendencia republicana, aunque resuelta en la monarquía constitucional de Amadeo I de Saboya. La noticia llegó a las 2 de la mañana del día 5 de octubre de 1868 por medio del vapor Cádiz. En ese momento, los adeptos al cambio de régimen, de monarquía absoluta hacia un abismo por desvelar, recorrieron las calles del centro de Santa Cruz, para llegar a la plaza de San Francisco, donde tenía su sede el ayuntamiento de la ciudad (exconvento franciscano de San Pedro de Alcántara) para constituir la Junta Superior de Gobierno de la Provincia de Canarias, con adhesión al gobierno provisional del general Serrano, tal y como relata fervorosamente el periódico republicano $\mathrm{El}$ Progreso de Canarias en su editorial (10/10/1868: 1).

Robayna no fue nombrado miembro de la Junta, pero personalmente la ratificó, como queda registrado en el periódico. Involucrado en la causa, poco tiempo después, en diciembre de 1868, se recoge la siguiente noticia:

Nuestro apreciable amigo D. Gumersindo Robayna acaba de pintar un interesante cuadro que representa los acontecimientos que tuvieron lugar en esta ciudad y en la calle de San Francisco durante la célebre mañana del 5 de octubre. Creemos, y así es también la opinión de personas competentes, que la obra del Sr. Robayna es digna del elevado concepto que merecidamente disfruta dicho artista. Por nuestra parte, le recomendamos al público, anunciando a la vez que se halla de manifiesto en la casa habitación del autor, calle de Robayna n. ${ }^{\circ} 4$, de 2 a 5 de la tarde (El Progreso de Canarias 14/12/1868: 3).

Es evidente que el cuadro quedó en propiedad del pintor durante un tiempo, pero, unos meses más tarde, quién sabe si poseído por un espíritu teñido de política popular, se publica la siguiente noticia:

En el teatro de la ciudad se verificará el domingo próximo a la una del día, la rifa del cuadro que ha pintado nuestro apreciable amigo D. Gumersindo Robayna, representando el movimiento revolucionario de esta Capital el 5 de octubre ( $E l$ Progreso de Canarias 01/07/1869: 2).

La noticia en sí parece anecdótica, pero tal vez se trate de uno de los mejores ejemplos, si no el mejor, del espíritu romántico que pudo aprender Robayna en París, en lo que respecta al sentido político del arte, pues ese cuadro, como hemos dicho, desconocido, fue pintado con el mismo ánimo puesto por Eugène 
Delacroix cuando, en 1830, pintó en La Libertad guiando al Pueblo (1830, Museo del Louvre, París); de hecho, Los sucesos del 5 de octubre en Santa Cruz de Tenerife retrataría la adhesión definitiva de la burguesía tinerfeña a un cambio de régimen.

El sentido dramático de Robayna también estuvo influido por las grandes composiciones teatrales (telones, etc.) que se pusieron de moda tanto en Italia como en Francia en la segunda mitad del siglo, para decorar los salones en fiestas o todo tipo de eventos sociales. A ello se debe la ejecución de las muselinas pintadas al temple y presentadas en 1875, denominadas panoramas. Una de ellas, la escalera de la Ópera de París (Fraga González 2011: 124), fue concebida como un gran escenario del poder de la burguesía. Esta obra, al igual que otras realizadas con la misma técnica, subrayaba la referencia a París, Florencia, y lugares teñidos de romanticismo, como la Alhambra de Granada, como escenarios perfectos para el ascenso burgués, clase social de éxito dentro del tercer estado y llamada a dirigir los destinos de la sociedad en los países avanzados. Sin embargo, esta pintura tiene algo especial. Está depositada en la Real Academia de Bellas Artes de San Miguel Arcángel de Santa Cruz de Tenerife y confirmamos su excepcionalidad al fijarnos en la escena tan detallada que reproduce el interior del gran vestíbulo de la Ópera Garnier. No hay duda que para pintarla, el artista (que no estuvo por entonces en París) debió de trabajar con una fotografía tomada en la capital francesa. Debe recordarse que la Ópera de París u Ópera Garnier fue inaugurada en enero de 1875, año en que Robayna ejecuta y presenta esta sarga. Es, por tanto, evidente, el empleo de la fotografía como fuente para la pintura moderna. Por otra parte, en la tela se muestra una escena de salón burgués poblado por hombres ataviados con levita y chistera, y en algunos casos, aún con el redingote, y mujeres vestidas a la última moda de París bajo la influencia del modista Frederick Worth (que abrió su casa de costura en París en 1858), luciendo ricos trajes de seda que Robayna se esmera en figurar, cayendo sobre la tournure, que en España conocemos por polisón. Tal vez, esta pintura sobre muselina no sea su obra más destacada, pero es la mejor evidencia de la sincronización de la vanguardia francesa con las aspiraciones burguesas santacruceras.

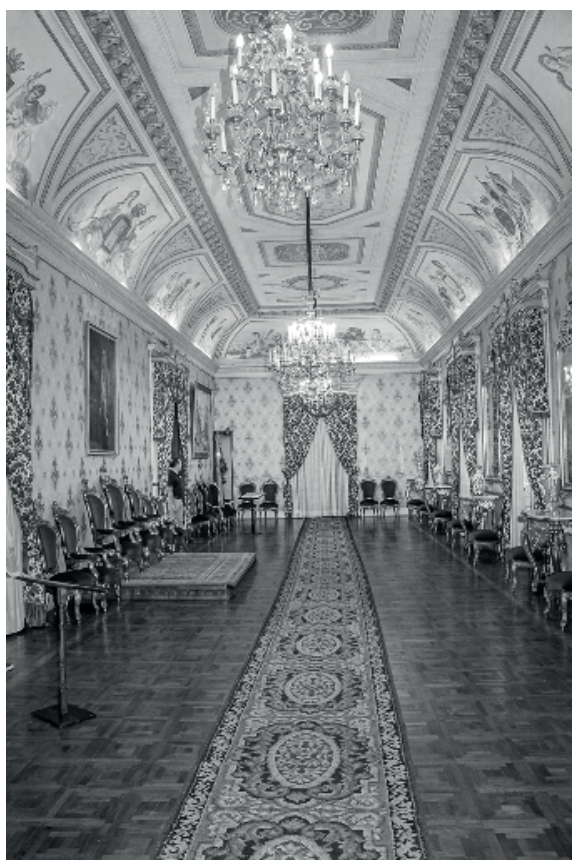

Fig. 7: Salón del Trono. Palacio de la Capitanía General de Canarias. Santa Cruz de Tenerife. Conjunto artístico concluido hacia 1881. Fotografía del autor. 
Pero las obras que, sin duda, mejor expresan el sentido estético francés son las pinturas decorativas al temple que ornan el Salón del Trono del palacio de la Capitanía General de Canarias en Santa Cruz de Tenerife, firmadas por Robayna en 1881 (bajo la alegoría del que muestra el reino de León). El deseo ornamental de dichas pinturas exalta tanto a España, suma de reinos, como a las islas Canarias, a través de sus escudos insulares (rodeados por alegorías, algunas, evidentes retratos de personas), al mismo tiempo que enaltecía al general Valeriano Weyler (1838-1930), capitán general de Canarias entre 18781883 y figura decisiva en los desastres del 98. Esta personalidad fue considerada en su tiempo como un militar civilista, que significa «el desplazamiento de los militares como elementos decisorios en los cambios de gobierno» (Seco Serrano 1999: 368) y, por ello, determinante en la vida política nacional.

Todos estos factores transforman una simple pintura decorativa en una realización a la francesa, en la que se mezcla el concepto histórico con la alegoría y la incorporación de retratos veraces, no ideales, tal y como se ornamentaban las residencias del tiempo de Napoleón III y continuaría haciéndose durante el último cuarto del siglo. Las referencias para pintar así tal vez le llegasen a través de las cartas recibidas asiduamente en Tenerife a su nombre o al de otros paisanos, remitidas por los amigos canarios residentes en Francia y que penetraban en las residencias parisinas del momento, entre ellos, cómo no, el omnipresente Berthelot.

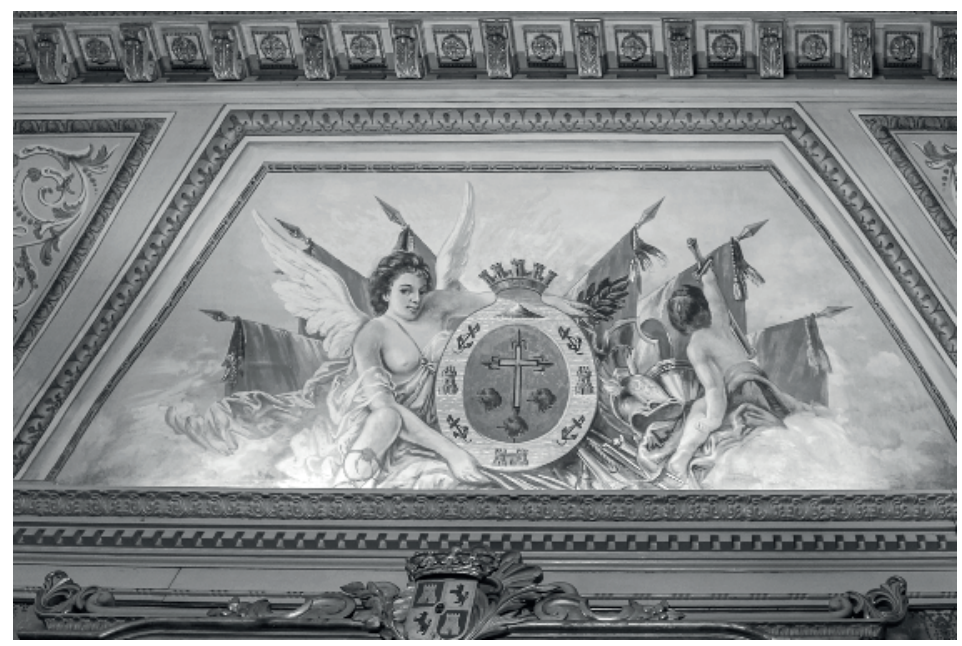

Fig. 8: Alegoría heráldica de Santa Cruz de Tenerife. Pintura al temple de Gumersindo Robayna, 1881. Techumbre del palacio de la Capitanía General de Canarias. Santa Cruz de Tenerife. Fotografía del autor.

Tras su fallecimiento en 1898, en sesión del Gabinete Instructivo celebrada en abril de 1899, se leyó un texto en su homenaje que repasaba su vida, firmado por el arquitecto Manuel de Cámara, y en él se recordaba el papel decisivo que Berthelot desempeñó en su vida, con las siguientes palabras: 
[...] Pero tal es el interés que le despierta el autor de ellas que a renglón seguido [Berthelot] de las observaciones que se le ocurren, le anima para que vaya a París a continuar sus estudios por las facilidades que allí encontraría, las cuales le expone con detalle y detenimiento perfecto de los Museos y talleres de afamados pintores de aquella época. Robayna siguió los consejos de Berthélot y aceptó sus excelentes recomendaciones para Mr. Lassalle, Garnier y otros famosos artistas, y después de haber permanecido dos años en Madrid se trasladó a París, donde al poco tiempo de llegar y después de recorrer los museos de aquella Capital, manifestaba el propósito de copiar el hermosísimo cuadro de la Concepción de Murillo y concibió el proyecto de un cuadro representativo del desembarco de Fernández de Lugo en las playas de Añaza. Mas cuando comenzaba a aprovecharse de su estancia en París, la noticia del a enfermedad de su padre, seguida a poco de la del fallecimiento acaecido el 24 de septiembre de 1854, le obligó a regresar a Tenerife [...] (Diario de Tenerife, 10/04/1899: 2).

Berthelot, en sí, no era un artista, pero cumplió una función esencial para la historia del arte: el papel de mecenas. Su mecenazgo no lo era en el sentido estricto que apreciamos en el Renacimiento o el Barroco, pero sí actuó como figura mediadora y benefactora entre los artistas y los centros de docencia, e incluso posibles clientes en Francia. La personalidad del naturalista ha sido trazada a lo largo de las páginas precedentes. No obstante, queremos dejar constancia de que el trabajo de Nathalie Le Brun sobre el legado que dejó a su

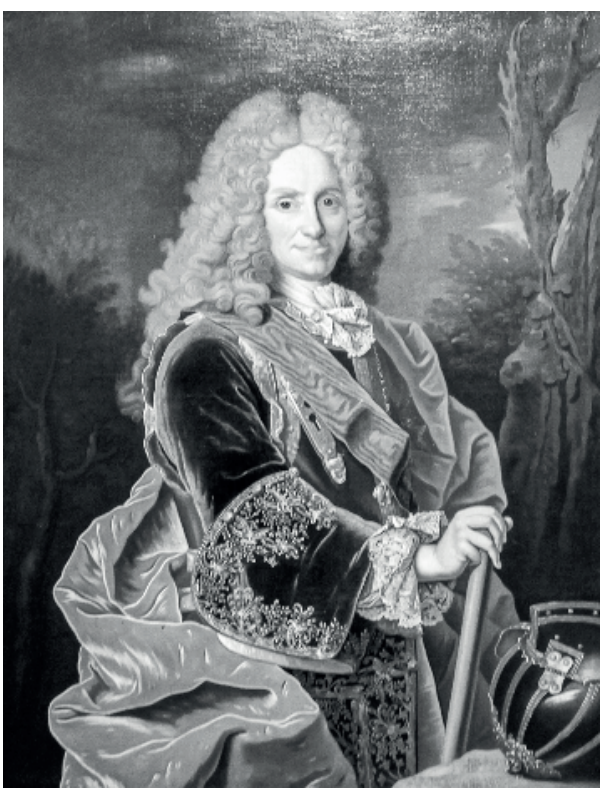

Fig. 9: Retrato de Felipe V. Óleo sobre lienzo, Jean Ranc o su círculo, c. 1724. Perteneció a la colección de Sabino Berthelot. Museo Municipal de Bellas Artes de Santa Cruz de Tenerife. Fotografía cortesía de Carlos Pallés Darias. muerte, acaecida el 18 de noviembre de 1880 , muestra que la colección de pinturas registradas es muy abultada, aunque la clasificación aportada en el momento en que se hace el inventario deja escaso lugar a la identificación actual de las mismas (Le Brun 2020: 397401), salvo en el caso de los retratos de Felipe $V$ e Isabel de Farnesio, donados al Ayuntamiento y depositados en el Museo Municipal de Bellas Artes de Santa Cruz de Tenerife, debidos al pincel de Jean Ranc (1674-1735) o su círculo, el retrato que le pintase Lassalle, y algunas otras. No obstante, dicho inventario asiente que a Berthelot le interesaban los géneros de pintura de su tiempo, e incluso poseía una «alegoría de la República Francesa con un león», un lienzo cargado de sentido político e ideológico que pudo impregnar a las élites sociales; 
si ese lienzo hubiese sido pintado por su amigo, el pintor romántico Auguste Couder (1789-1873), como apunta Le Brun, hubiese sido una de las mejores obras artísticas francesas que pudo conocer Santa Cruz en aquel siglo y, quién sabe, una influencia para Robayna en las pinturas del citado Salón del Trono.

Por todo lo referido, podemos afirmar que Sabino Berthelot fue el factótum de la vida artística de la segunda mitad del siglo xIX y roció de estética francesa a los artistas y a la sociedad tinerfeña. Así, pues, el éxito del artista quedaría innegablemente asociado a su proximidad a Francia, y el viaje a París o, como mínimo, el contacto indirecto con la realidad artística francesa, sería un elemento indispensable en la formación intelectual de todo autor cultural. Su presencia nunca es evidente o muy explícita en el campo del arte, pero el rastreo de la prensa nos devuelve numerosísimas referencias al cónsul francés como impulsor de las actividades expositivas o del ánimo a los artistas para mejorar su formación. Por ello, debe ser considerado como uno de los pilares que justifican el prestigio de Francia en Tenerife.

\section{Desde Francia hacia Canarias}

Algunos de los intelectuales y artistas canarios tuvieron la fortuna de aprender de Francia en Francia, de asistir a sus exposiciones, conocer los museos, disfrutar de la vida social y cultural y, en consecuencia, de influir en los amigos y familiares que quedaron en las Islas, para que el prestigio francés aumentase día a día. En este apartado podemos apreciar dos cuestiones: por un lado, el relato de la vida cotidiana que escriben los canarios establecidos en Francia, algunos aludiendo al genuino pintor canario establecido en París: Manuel González Méndez. Por otro lado, las crónicas enviadas desde Francia sobre cuestiones generales que pretenden aportar nueva luz e influir en Canarias sobre asuntos de interés general, en especial, el mejor aprovechamiento de los productos agrarios e industriales canarios para ser expuestos y, tal vez, comercializados fuera de las Islas, gracias a las exposiciones universales, o el fomento del estudio como única forma de progreso.

En ambos sentidos, el medio por excelencia para dar a conocer en Tenerife esas ideas provenientes de París fue la Revista de Canarias, dirigida por el republicano Elías Zerolo Herrera (Lanzarote, 1849-París, 1900), cuya vocación política, a la vez que cultural, lo animó a ser uno de los fundadores del Gabinete Instructivo en 1869 y a poner en marcha el proyecto editorial que hemos mencionado, publicado entre 1878 y 1882. Su persona fue valorada y definida por el historiador Marcos Guimerá, como el intelectual puro (1996: 659-702). Entre los colaboradores se hallaba Patricio Estévanez y Murphy (1850-1926), literato y periodista republicano que, tras el fracaso de la I República se exilió en París hasta 1880, cuando regresó a Tenerife, enviando desde allí numerosas crónicas de interés para Canarias. Sus traducciones y otras obras literarias, así como su popularidad en la capital francesa, le valieron el apodo de «cónsul general isleño» (Guimerá Peraza 1974: 92). A pesar de que aún joven retornó a Tenerife, el espíritu francés presidió siempre su ánimo. Ya en el n. ${ }^{\circ} 1$ de la Revista de Canarias se 
quejaba del escaso éxito de la representación canaria en la Exposición Universal de París de 1878, celebrada en el Campo de Marte, por la mala presentación de los productos. Más allá de esta cuestión, destacaba, en cambio, la calidad de la obra de Manuel González Méndez al presentar los cuadros Pescador de Güímar, también conocido como Juan Chichí (Museo Municipal de Bellas Artes de Santa Cruz de Tenerife) y Fiesta palmera (Ayuntamiento de Santa Cruz de La Palma):

Veinte y nueve son los expositores canarios cuyos productos figuran en el campo de Marte y sus anexos: Manuel González Méndez con dos notables cuadros al óleo que representan: una fiesta en un pueblo de La Palma y un pescador de Güímar; el Sr. Dr. Chil, de Las Palmas, que presenta objetos de barro de los guanches [...] (Estévanez, Revista de Canarias 8/12/1878: 9).

La admiración por cómo se organizaban y resolvían en París las actividades benéficas, aunque revestidas de un trasfondo social de gran empaque, es la reseña firmada por Estévanez en esa ciudad el 19 de diciembre de 1879 sobre la gran fiesta celebrada para recaudar fondos para socorrer a los damnificados en Murcia por unas trágicas inundaciones. Se trata de un entretenido artículo que narra esa cuestación/fiesta en el hipódromo de París, en la que participaron toreros, se construyeron decorados reproduciendo la Alhambra y la Giralda, los hombres fueron de frac, muchas mujeres españolas lucían mantillas y en la que participó la actriz Sara Bernhardt; en definitiva, que fue una grandiosa fiesta de homenaje a España (Estévanez, Revista de

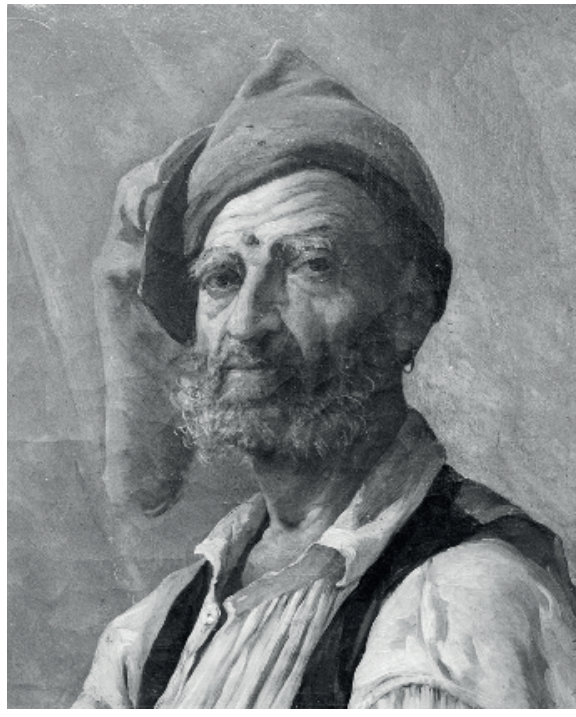

Fig. 10: Pescador de Güímar o Juan Chichí. Óleo sobre lienzo, Manuel González Méndez, 1878. Museo Municipal de Bellas Artes de Santa Cruz de Tenerife. Fotografía del autor. Canarias 23/01/1880: 24-26).

Otro de los colaboradores fue Juan Maffiotte y La Roche (1855-1887), hijo de Pedro Maffiotte. En 1873 marchó a Madrid para estudiar ingeniería, siguiendo luego hacia París, ciudad desde la que envió numerosos artículos a la prensa tinerfeña y donde fue compilando información para redactar un Glosario de canarismos, que ha sido dado a conocer por Cristóbal Corrales y Dolores Corbella (1993). Pero lo que nos interesa es la amistad que lo unió al pintor Manuel González Méndez, de quien remitió crónicas encendidas de admiración por la calidad de su obra. Envió a la Revista varios artículos que pretendían el fomento en Canarias de los estudios generales, y específicos, en lo relacionados con la botánica y la agricultura, dada su importancia para la realidad insular. Desde la perspectiva artística, nos interesan los aludidos reportajes sobre el 
pintor palmero Manuel González Méndez, publicados en dos números en 1880. Para el n. ${ }^{\circ} 48$, redactó un texto rico en detalles en el que informa de cómo conoció a Méndez en el café Universal de Madrid, lugar de tertulia de los canarios en la capital, y se sorprendió de no haber oído hablar sobre él en las Islas. Fueron juntos al Museo del Prado y allí, gracias a Méndez, descubrió otra visión de la pintura, culta y refinada. Lo elogia como un gran artista, como un genio. Alaba sus retratos por ser naturalistas, aunque nunca pintase exactamente al modelo. Lo invita a que se dedique a la gran pintura de Historia, aunque valora sus temas historicistas y costumbristas de los siglos XVII y XVIII. Sin embargo, censura su cuadro Fiesta palmera por parecerle de menor valor.

De él, entre muchas cosas, dice:

Lo que yo no me podía explicar es que, siendo Manuel G. Méndez hijo de Canarias, no hubiera oído hablar de él en toda mi vida. Ahora me doy cuenta exacta del fenómeno; porque en Canarias, como en muchas otras partes, no son conocidos sino los periodistas que hacen ruido, los oradores de clubs en tiempos de libertad, los grandes cosecheros de cochinilla y los que se saben dar lustre. El verdadero talento es modesto, según dicen: aunque yo opino que es muy conveniente soplar a dos cornetas la trompeta de la fama, y que no tiene menos talento el que sopla más fuerte (Maffiotte La Roche, Revista de Canarias 23/08/1880: 249-251).

En el n. ${ }^{\circ} 49$, segunda parte de su extenso trabajo sobre el pintor, destaca sus cuadros de pequeño y gran formato, como la Cocina bretona (Museo Municipal de Bellas Artes de Santa Cruz de Tenerife), y compara su obra a la del pintor Carolus Duran:

Decía, pues, que yo no necesito comparaciones, más o menos desprovistas de fundamento, para decir y asegurar positivamente que el retrato de Juan Real que ha hecho este año es una obra excelente y que tiene cualidades de primer orden. Es verdad que todos los buenos pintores se parecen en algo, y si en otra cosa no, en que son buenos; es mucha verdad que todos aprenden estudiándose mutuamente. Pero no lo es tanto que Méndez haya ido a estudiar a Carolus Duran, teniendo los excelentes modelos que se llaman van Dyck y Velázquez, y ese otro que es modelo de todos y que apellidan Naturaleza [...] (Maffiotte La Roche, Revista de Canarias 08/09/1880: 275-276).

Así, pues, a través de Juan Maffiotte, podemos adivinar la personalidad del artista canario por excelencia, establecido en París. El palmero Manuel González Méndez (1843-Barelona, 1909) se formó en el entorno de la recién creada Academia de Bellas Artes de Santa Cruz de Tenerife. Marchó a París en 1870, nada menos, por lo que vivió la derrota en Sedán de Napoleón III y la caída del II Imperio, la revuelta de la Commune de París en 1871 y sus terribles consecuencias contra el arte, y la instauración de la III República francesa. A pesar del clima literalmente explosivo que se vivía en Francia, ingresó como alumno de la École des Beaux-Arts de París, uno de los tantos alumnos extranjeros que formaron el entorno del pintor más reputado de su tiempo, Jean-Léon Gérôme (1824-1904), preferido por Eugenia de Montijo y primer crítico del nuevo arte 
que, en la década de 1860, representaba ese grupo, despectivamente denominado los impresionistas ${ }^{4}$.

Lo que nos interesa de la vida parisina de González Méndez, ciudad en la residió hasta su muerte, salpicada de varios viajes a Canarias a lo largo de las décadas, fue que dejó de interesarle el paisaje romántico para profundizar en el verismo del retrato, con mayor carga psicológica, próximo a Carolus Duran, como señala Maffiotte. Una de las obras que escenifican este concepto sería el retrato de Juan Maffiotte La Roche (colección particular, Santa Cruz de Tenerife), firmado y fechado en 1879, un año antes de que Maffiotte escribiera el artículo referido, lo que demuestra una sólida amistad entre ambos. También destacó en escenas de personajes populares, como el citado Juan Chichí, o Juan Real, que indican la democratización iniciada en su arte, más allá de la mera percepción romántica (y que, por tanto, incluye la perspectiva burguesa).

También ejecutó lo que denominamos cuadros de subsistencia, es decir, cuadros de formato pequeño o mediano de asuntos variados, sobre todo de naturaleza histórico-literaria, con escenas alusivas al Antiguo Régimen, que estaban de moda en París por aquellas fechas y tenían fácil salida en el mercado del arte. No obstante, su pintura crecía al abordar temas alegóricos o simbólicos, que reflejan la vivencia parisina experimentada junto al mencionado Gérôme, como se aprecia en las pinturas mitológicas del Gabinete Literario de Las Palmas o el lienzo que cubre el salón de plenos del Ayuntamiento de Santa Cruz de Tenerife (ambos, encargos realizados en 1902). La cuestión es que todo este bagaje lo transmitía por cartas y oralmente a sus amigos de Tenerife, tanto del entorno académico como a los pintores locales. Con ello, el arte tinerfeño del último cuarto del siglo XIX quedó empapado del gusto variable parisino, como se aprecia en los retratos de Truilhé, Robayna, Nicolás Alfaro y, en realidad, de todos los pintores de la época, pues González Méndez,

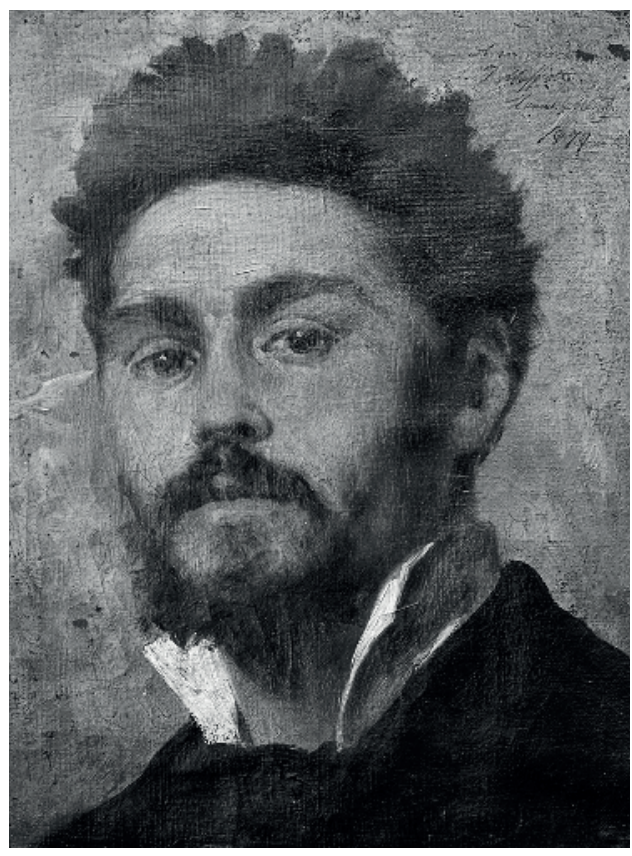

Fig. 11: Retrato de Juan Maffiotte La Roche. Óleo sobre lienzo, Manuel González Méndez, 1879. Colección particular, Santa Cruz Tenerife. Fotografía cortesía de Carlos Pallés Darias.

4 Sobre los motivos que decidieron su marcha a París y su establecimiento, véase Alloza Moreno 1981, p. 13-38. 
el artista canario en París, fue la gran referencia artístico-social en la época, un apoyo que no se trasladó al ámbito económico, pues nunca recibió ayudas de las autoridades canarias. Sin embargo, a él cabe, más que a nadie, el prestigio de Francia en las artes.

Otro de los entusiastas de lo francés fue el político y poeta grancanario Amaranto Rodríguez de Escobar y Luján (1835-1912), autor de una crónica deliciosa sobre la ciudad de Marsella (tan importante para el comercio canario) bajo el título «Un día en Marsella». Como ejemplo, copiamos el siguiente párrafo:

El viejo Marsella es un capítulo aparte de la población principal. Hállase aquel cuartel atravesado por la calle Imperial, hoy de la República, que desde el Puerto viejo conduce directamente a la plaza de la Joliete [Joilette], cuyo barrio, completamente nuevo, se compone de magníficas y elegantes casas en construcción con calles rectas y espaciosas que forman un verdadero tablero de ajedrez [...] (Rodríguez de Escobar, Revista de Canarias 23/06/1879: 210).

La misma apreciación podemos hacer del abogado y naturalista tinerfeño Domingo Bello Espinosa (1817-1883), que fue alcalde de Santa Cruz en la década de 1840, y que luego partió a Puerto Rico para regresar a Tenerife en 1878 . Inició entonces su colaboración con la Revista de Canarias, donde publicó, en 1881, dos artículos titulados "Carta de un tacorontero en París», donde estimulaba el viaje a la capital de Francia para absorber la verdadera cultura. Se trata de un relato publicado en dos números donde narra su reciente viaje a París acompañado de un nativo, monsieur Verdier, un auténtico y honrado hombre del pueblo que lo lleva a varios lugares notables. El autor, durante toda la narración, destaca la majestuosidad de la ciudad, que las fotografías no consiguen captar adecuadamente, así como la fuerza y la verdad de los personajes populares

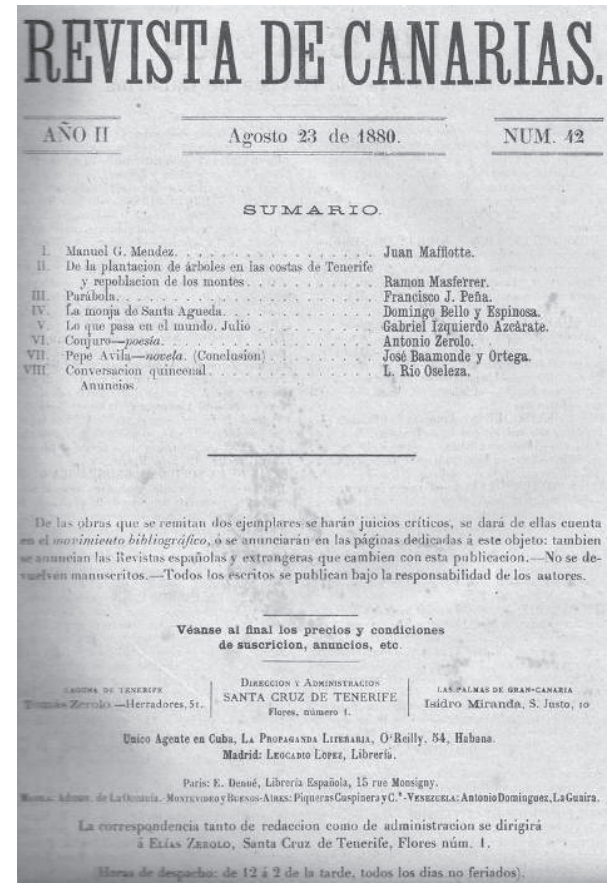

Fig. 12: Portada de la Revista de Canarias, n. ${ }^{\circ} 42$ (23 agosto de 1880). Contiene un artículo sobre Manuel González Méndez, por Juan Maffiotte. Colección particular. Fotografía del autor. (Bello Espinosa, Revista de Canarias 08/01/1881:1-3, 23/01/1881: 21-26).

Para concluir este trabajo que valora el prestigio de Francia en la sociedad tinerfeña, nada mejor que la carta publicada por la prensa santacrucera en agradecimiento a la República Francesa por las ayudas encauzadas desde allí para socorrer a los murcianos tras las graves inundaciones de 1879, asunto 
ya tratado por Estévanez. Está firmada por las redacciones de Las Noticias, El Memorándum, la Revista de Canarias, el Eco del Comercio y El Progreso de Canarias, el 8 de enero de 1880, y encaminada al cónsul de Francia en Canarias, el barón Chasserieau:

[...] Parte el Archipiélago Canario de la hidalga nación favorecida, ha designado a la prensa de esta capital por órgano de esta manifestación; y asociada a diversas corporaciones, fundidas en un afecto de gratitud y simpatía, os ruega trasmitáis estos sentimientos sinceros y cordiales a la prensa de vuestro país y al Gobierno que os confió la misión que con tanto acierto llenáis. Decidles, señor cónsul, que en este pedazo de la tierra española, que ama tanto su bandera como su honra, encontrarán los franceses la hospitalidad con que los buenos reciben a sus huéspedes; el respeto y la consideración que los agradecidos tributan a los generosos y el cariño que se deben los hijos de dos pueblos amigos destinados tal vez a llenar en no interrumpida paz altos fines en la historia de la humanidad [...] (Revista de Canarias 23/01/1880: 29).

\section{Conclusiones}

Dichas palabras son el mejor colofón para este estudio, pues Francia no es percibida, en realidad, como un país vecino y hermano a ratos (la invasión napoleónica no había sido olvidada), sino como la cuna de la civilización, el espejo en el que Canarias debía mirarse, pues los cambios políticos operados allí desde la proclamación de la III República francesa, en 1870, estimulaba los deseos de muchos de los protagonistas de la cultura y el arte en las Islas durante la segunda mitad del siglo, que trufaban de ideas republicanas los estertores absolutistas del reinado de Isabel II, la frustrada república española y los inicios del reinado parlamentario de Alfonso XII. Las artes se percibían como un medio para contar y cantar la verdad. La sinceridad de los retratos, el gusto oscilante de los paisajes (entre la franqueza del realismo y la imaginación expresada en las manchas de color), así como la libertad en la elección de los temas iconográficos, tenían su origen en París. Las más altas intenciones de Sabino Berthelot, amante del conocimiento racionalista y de la observación, se volcaba en la búsqueda de la verdad en el paisaje y el entorno, que se ejemplificaba en las obras de Truilhé y Robayna.

A su vez, la pintura de Robayna, sobre todo la historicista, que buscaba un compromiso entre el arte y la política nacida de la trasposición de la pintura de Historia, aprendida en las exposiciones de París, tuvo su inicio en la Fundación de Santa Cruz, pero culminó en el compromiso político directo en la desparecida pintura de los Sucesos del 5 de octube de 1868. Esta obra, a su vez, entroncaba con el pensamiento político de Elías Zerolo y Patricio Estévanez, que, junto con Juan Maffiotte La Roche, todos idealistas, todos residentes en París en diferentes momentos, protagonizaron muchos de los artículos que relacionaban arte, ciencia y política, promovidos en la Revista de Canarias y en otros medios de comunicación tinerfeños en la segunda mitad del siglo. 
Y sobrevolando todo ese escenario desde París, la pintura de Manuel González Méndez, que deseaba gustar al público, que pintaba para vender con la eterna esperanza de vivir del oficio de pintor, pero también sensible con su tierra, con los tipos populares, con la vida sencilla que enlazaba con los ideales de la sociedad burguesa republicana o simpatizante con una monarquía constitucional y parlamentaria.

Podemos concluir que los principales animadores y cultivadores de la pintura en Santa Cruz de Tenerife durante la segunda mitad del siglo XIX buscaban la verdad, la autenticidad del mensaje, la sencillez del medio técnico y aproximar el gran arte al mundo popular. Y el telón de fondo, el punto de fuga de esa composición, era el sempiterno prestigio de Francia.

\section{Bibliografía}

Alloza Moreno M.A., 1981, La pintura en Canarias en el siglo XIX, Santa Cruz de Tenerife, Aula de Cultura de Tenerife.

Bello Espinosa D. 08/01/1881. "Carta de un tacorontero en París», Revista de Canarias n. ${ }^{\circ}$ 4, p. 1-3.

Bello Espinosa D. 23/01/1881, "Carta de un tacorontero en París II», Revista de Canarias n. ${ }^{\circ} 5$, p. 21-26.

Borges E. et al., 2011, «Extracción de colorantes naturales a partir de la cochinilla (Dactylopius coccus) de Lanzarote», Estudios Canarios. Anuario del Instituto de Estudios Canarios, La Laguna, n. ${ }^{\circ}$ 55, p. 253-277.

Cámara M., 10/04/1899, «Sesión del Gabinete Instructivo en homenaje a Sabino Berthelot», Diario de Tenerife, Santa Cruz de Tenerife, p. 2.

Castro Brunetto C.J., 2018, «Identidades masculinas y moda en la pintura española del siglo XIX», Revista De Arte, n. ${ }^{\circ}$ 17, p. 149-163.

Cioranescu A., 1979, Historia de Santa Cruz de Tenerife, Santa Cruz de Tenerife, Servicio de Publicaciones de la Caja General de Ahorros de Santa Cruz de Tenerife, vol. 4.

Dugour J.D., 31/12/1853, «Acta de la Sociedad Filarmónica», Eco del Comercio, Santa Cruz de Tenerife, p. 3.

Estévanez P., 8/12/1878, «Correspondencia de París: los productos canarios en la exposición», Revista de Canarias n. ${ }^{\circ}$ 1, p. 9.

Ferrer Álvarez M., 2014, «La condición social del pintor de la modernidad en París en la segunda mitad del siglo XIX», Saitabi: revista de la Facultat de Geografía i Història, nros. 64-65, p. 225-239.

Fraga González C., 1999, El arquitecto Manuel de Oraá y Arcocha (1822-1889), La Laguna, Instituto de Estudios Canarios.

Fraga González C., 2011, «Gumersindo Robayna y la Real Academia de Bellas Artes», Anales [2010], Islas Canarias, Real Academia Canaria de Bellas Artes de San Miguel Arcángel, p. 121-126. 
Fraga González C., 2013, «Bicentenario de Cirilo Truilhé (1813-1904), pintor y académico», Anales [2013], Islas Canarias, Real Academia Canaria de Bellas Artes de San Miguel Arcángel, p. 131-153.

Fraga González C., 2018, «Jacobina Bello y Espinosa, pintora del siglo xIx: retratos de la familia Regalado», Catharum. Revista del Instituto de Estudios Hispánicos de Canarias, n. ${ }^{\circ}$ 17, p. 45-54.

Guimerá López C., 1993, «Bravo Murillo, el ministro de las franquicias canarias (Apuntes para una biografía)» Estudios Canarios. Anuario del Instituto de Estudios Canarios, La Laguna, n.os 36 y 37, p. 41-53.

Guimerá Peraza M., 1974, «Patricio Estévanez, periodista y ciudadano», El Museo Canario, Las Palmas de Gran Canaria, El Museo Canario, tomo XXXV, p. $89-122$.

Guimerá Peraza M., 1996, «Don Elías Zerolo, el intelectual puro [1848-1900]», Anuario de Estudios Atlánticos, Las Palmas de Gran Canaria: Casa de Colón, n. ${ }^{\circ} 42$, p. $659-702$.

Hernández Socorro M.R., 1998, «Endogamia y cosmopolitismo en la pintura canaria del siglo xıx: el periplo artístico de ida y vuelta», en La pintura del siglo XIX en las colecciones canarias: los cimientos de la modernidad. Islas Canarias, Caja General de Ahorros de Canarias. Casa de Colón, p. 39-65.

Le Brun N., 2020, «El legado de Sabin Berthelot: una primera aproximación a su biblioteca y sus colecciones (1878-1894)», Vegueta. Anuario de la Facultad de Geografía e Historia, n. ${ }^{\circ}$ 20, Universidad de Las Palmas de Gran Canaria, p. 371-412.

Maffiotte La Roche J., 23/08/1880, «Manuel González Méndez», Revista de Canarias n. ${ }^{\circ} 48$, p. $249-251$

Maffiotte La Roche J., 08/09/1880, «Manuel González Méndez II», Revista de Canarias n. ${ }^{\circ} 49$, p. $274-276$.

Maffiotte La Roche J. 1993, Glosario de canarismos [Edición de Corrales, C. y Corbella, D.], La Laguna, Instituto de Estudios Canarios.

Martín López D., 2009, «Visionando y restaurando la estética masónica en el paisaje urbano: el ejemplo de Canarias», Zainak, n. ${ }^{\circ}$ 31, vol. 1, p. 503-525.

Martínez de la Peña D., Rodríguez Mesa M., Alloza Moreno M.A., 1987, Organización de las enseñanzas artísticas en Canarias, Santa Cruz de Tenerife.

Murray, E., 2004, Recuerdos de Tenerife [prólogo de José Luis García Pérez], Santa Cruz de Tenerife, Ediciones Idea.

Rodríguez de Escobar A., 23/06/1879, «Un día en Marsella», Revista de Canarias, n. ${ }^{\circ} 14$, p. $209-211$.

Rosenblum R., Janson H.W., 1992, El arte del siglo XIX, Madrid, Akal.

Rumeu de Armas A., 1997, Luis de la Cruz, Islas Canarias, Viceconsejería de Cultura y Deportes del Gobierno de Canarias, "Colección Biblioteca de Artistas Canarios n. ${ }^{\circ} 33 »$. 
Seco Serrano C., 1999, "Valeriano Weyler, modelo de militar civilista», Boletín de la Real Academia de la Historia, Madrid, Real Academia de la Historia, tomo CXCVI, n. ${ }^{\circ}$ 3, p. 363-420.

Siemens L., 2013, «Breve historia de la Real Academia Canaria de Bellas Artes», in La Academia y el Museo. Conmemoración de un centenario, 1913-2013, Excmo. Ayuntamiento de Santa Cruz de Tenerife/Organismo Autónomo de Cultura, Real Academia Canaria de Bellas Artes de San Miguel Arcángel, p. 11-22.

Fuentes hemerográficas citadas

Diario de Tenerife, Santa Cruz de Tenerife, 1889, 1891, 1894, 1899.

Eco del Comercio, Santa Cruz de Tenerife, 1856-1858, 1860, 1861, 1864.

El Eco de la Juventud, Santa Cruz de Tenerife, 1848.

El Instructor y el Recreo de las Damas, Santa Cruz de Tenerife, 1857.

El Insular, Santa Cruz de Tenerife, 1868.

El Noticioso de Canarias, Santa Cruz de Tenerife, 1852.

El Progreso de Canarias, Santa Cruz de Tenerife, 1868, 1869.

La Ilustración de Canarias, Santa Cruz de Tenerife, 1883.

La Opinión, Santa Cruz de Tenerife, 1892. 